\title{
Serum inflammatory markers as predictors of neurological status in patients with stroke in the course of hypertension: a two-center study
}

\author{
Martyna Anna Nowak, Maria Magdalena Nowak, Paula Irmina Walczak, Maciej Wojciech Olszewski, \\ Natalia Niedziela, Paweł Warmus, Monika Adamczyk-Sowa
}

Department of Neurology, SMDZ in Zabrze, Medical University of Silesia in Katowice, Poland

\begin{abstract}
Introduction. Every year, 60.000 people have stroke incidents in Poland. Despite the fact that it can be prevented, stroke remains the leading cause of morbidity and mortality worldwide. Hypertension is one of the leading risk factors for the stroke incident. The aim was to assess the relationship between inflammatory markers and clinical status of hypertensive patients with the stroke.

Material and methods. 713 patients with stroke in the course of hypertension from the Departments of Neurology in Bytom and Zabrze were enrolled in the retrospective study. They were divided into groups: N1, R1 (with improvement in NIHSS and Rankin results, respectively) and N2, R2 (with deterioration or no changes in NIHSS and Rankin between the day of admission and discharge).

Results. The majority of patients were females [\%] (51.5 vs 48.5). Women were significantly older than man [years] (78.0 vs 69.0, $\mathrm{P}=0.001$, respectively) and had higher NIHSS results at admission [points] $(6.0$ vs 5.0, $\mathrm{P}=0.001$, respectively). There were significant differences in the serum CRP $[\mathrm{mg} / \mathrm{l}](4.75$ vs $9.40, \mathrm{P}=0.001)$ and $\mathrm{WBC}\left[10^{3} / \mu \mathrm{L}\right]$ ( 8.58 vs $9.02, \mathrm{P}=0.006$ ) between $\mathrm{N} 1$ and $\mathrm{N} 2$, respectively and between $\mathrm{R} 1$ and $\mathrm{R} 2$ : $\mathrm{WBC}(8.50$ vs $9.00, \mathrm{P}=0.006)$ and CRP (4.20 vs 8.70, $\mathrm{P}=0.001)$, respectively. A significant correlation between CRP and NIHSS on admission was observed $(\mathrm{R}=0.191, \mathrm{P}<0.05)$. NIHSS and Rankin score on admission were correlated with age $(\mathrm{R}=0.212$, and $\mathrm{R}=0.231, \mathrm{P}<0.05$, respectively). CRP was related with the volume $\left[\mathrm{cm}^{3}\right]$ of lesions in $\mathrm{CT}(\mathrm{R}=0.170, \mathrm{P}<0.05)$. Conclusions. Inflammation seems to be associated with the worse neurological status of patients with stroke and hypertension. Age and sex affect the clinical course of stroke. CRP may indicate the size of changes in CT.

Key words: stroke, hypertension, NIHSS, Rankin, inflammation, CRP, WBC
\end{abstract}

Arterial Hypertens. 2018, vol. 22, no. 2, pages: 87-94

DOI: $10.5603 / A H .2018 .0009$

\section{Introduction}

Stroke, in its classic definition, is interpreted as a neurological deficit caused by an acute focal damage of the central nervous system and is one of the leading causes of disability and mortality worldwide [1].
In 2005, the incidence of stroke was estimated at 16 million worldwide, predicting that in 2030 this figure would increase to 23 million [2]. In 2013 in the United States stroke was the fifth leading cause of death. Despite declining mortality, nearly 800000 people per year experience a new or recurrent stroke,

Address for correspondence: Paula Irmina Walczak

Department of Neurology, SMDZ in Zabrze, Medical University of Silesia in Katowice, Poland, ul. 3 maja 13-15, 41-800 Zabrze, Poland; tel.: 538343-039, e-mail: paulaw10@op.pl 
and about 140,000 of stroke victims die [3]. Due to the widespread access to a specialist treatment and improved medical standards in developed countries, the survival rate of stroke victims should increase.

According to researchers, stroke remains the leading preventable cause of morbidity and mortality worldwide, and it can be prevented by e.g. lifestyle modification, pharmacological treatment of hypertension, hypercholesterolemia or atrial fibrillation (AF) [4]. It is worth emphasizing that hypertension substantially increases the risk of stroke, accounting for as much as $52 \%$ of cases [5].

In order to determine the degree of neurological deficits after stroke, and to predict the outcome, specific scales were created, such as the National Institute of Health Stroke Scale (NIHSS), the modified Rankin scale (mRS) and Barthel index (BI) [6].

The aim of our study was to assess the association between sex, age and the severity of stroke in patients with hypertension. Specifically, the study aimed to evaluate the inflammatory markers and the CT-assessed lesions volume on the clinical outcome of patients.

\section{Material and methods}

Our study is a retrospective analysis of medical records from two referral centers located in Upper Silesia region, Poland. Initially, we analyzed the records of 1000 patients hospitalized between 2013 and 2016 who were diagnosed with cerebrovascular diseases from the Departments of Neurology in Bytom, and Zabrze. All patients were treated for primary hypertension, diagnosed according to the European Societies of Hypertension and Cardiology Guidelines (2013) [7, 8].

The inclusion criteria were as follows: age $>35$ years, inhabitancy of the Upper Silesia region, diagnosis of stroke based on the World Health Organization (WHO) definition, primary hypertension prior to stroke or TIA, ongoing antihypertensive therapy. The exclusion criteria were as follows: secondary stroke caused by trauma, brain tumor or brain metastases, persistent migraine aura without infarction, Todd's paresis and signs of infection.

Based on patients' medical history, 713 patients met primary inclusion criterion; 661 were diagnosed with ischemic stroke, 50 with hemorrhagic stroke and 2 with a transient ischemic attack (TIA).

211 patients were excluded because they were not diagnosed with primary hypertension prior to admission. Another 49 patients admitted that they did not take medications against hypertension, 15 were found to suffer from upper respiratory infection before admission, 6 had a secondary stroke caused by trauma, 3 were suspected of brain tumor, 2 were diagnosed with persistent migraine aura without infarction and 1 had documented Todd's paresis.

Clinical state of the patients was evaluated upon admission before the treatment was introduced. The patients' data were re-evaluated at discharge using the NIHSS and RANKIN scales. Similarly, the CT-based size of stroke lesion and the change of its volume $\left[\mathrm{cm}^{3}\right]$ were analyzed in two corresponding timepoints: at baseline (CT1), and at discharge (CT2).

As the study design was retrospective based on the analyses of available clinical data, no Ethical Committee Board approval was mandatory, as regulated by the rules and regulations of our Center.

\section{Statistical analysis}

Continuous variables were presented as the median and an interquartile range (IQR). The categorical variables data were presented as percentages. The groups were compared using the nonparametric Mann-Whitney $U$ test. The analysis of correlations between variables was conducted using the Spearman rank correlation analysis. Statistical significance was defined as $\mathrm{P}<0.05$. Statistical analyses were performed using the software Statistica 13 (Statsoft, Tulsa, Oklahoma, USA).

\section{Results}

The median age in the whole study group was 75.0 years [65.0-81.0]. $358(50.21 \%)$ of the participants were females and 355 (49.79\%) were males. Women and men significantly differed in age. The median age was 78.00 [70.00-83.00] and 69.00 [63.00-78.00], $\mathrm{P}<0.001$ for females and males, respectively. The comparison of the clinical data with respect to sex was presented in Table I. Females and males had significantly different percentage of patients with stenosis of cervical arteries, myocardial infarction and AF. They also differed in NIHSS score, Rankin score but they did not differ in the volume of stroke lesion in CT. In general, patients had from 1 to 4 stroke lesions detected in CT, however, the majority, of them $(93.04 \%)$ had 1 lesion.

The study group was divided depending on the NIHSS and RANKIN results on the day of admission and discharge into groups: patients with improvement in NIHSS (N1; $\mathrm{n}=487)$, with deterioration or no change in NIHSS or patients who were found dead $(\mathrm{N} 2 ; \mathrm{n}=225)$, with improvement 
Table I. The comparison of the clinical state in the whole study group divided according to sex

\begin{tabular}{|c|c|c|c|}
\hline Issue & Female $(n=358)$ & Male $(n=355)$ & $\mathbf{P}$ \\
\hline Stenosis of cervical arteries (\%) & 25.42 & 38.31 & $<0.001$ \\
\hline Myocardial infarction (\%) & 29.61 & 39.72 & 0.005 \\
\hline Atrial fibrillation recognized prior to stroke (\%) & 29.05 & 18.31 & 0.001 \\
\hline Atrial fibrillation present during hospitalization (\%) & 34.64 & 23.45 & 0.001 \\
\hline NIHSS on admission & $6.00[3.00-12.00]$ & $5.00[3.00-8.00]$ & $<0.001$ \\
\hline NIHSS at discharge & $\begin{array}{c}3.00[2.00-10.00] \\
n=308^{*}\end{array}$ & $\begin{array}{c}3.00[1.00-5.00] \\
n=317^{*}\end{array}$ & 0.001 \\
\hline Rankin on admission & $4.00[3.00-5.00]$ & $4.00[3.00-4.00]$ & $<0.001$ \\
\hline Rankin at discharge & $\begin{array}{c}3.00[2.00-5.00] \\
n=306^{*}\end{array}$ & $\begin{array}{c}2.00[1.00-4.00] \\
\mathrm{n}=317^{*}\end{array}$ & $<0.001$ \\
\hline The sum of the volume of all lesions in CT1 $\left[\mathrm{cm}^{3}\right]$ & $3.50[1.60-12.56]$ & $4.00[1.82-12.00]$ & 0.79 \\
\hline The sum of the volume of all lesions in CT2 [cm³] & $3.35[1.70-11.22]$ & $2.80[1.40-12.00]$ & 0.23 \\
\hline
\end{tabular}

*In the rest of cases death was found; the sum of the volume of all lesions in patient in CT1 was 3.85 [1.70-12.00] $\mathrm{cm}^{3}$ and in the CT2 at the end of hospitalization was 3.00 [1.50-11.90] $\mathrm{cm}^{3}$. The greatest lesion in CT1 was $3.50[1.70-10.08] \mathrm{cm}^{3}$ and in the CT2 was $3.00[1.5-11.25] \mathrm{cm}^{3}$. In 50.70\% [72*] of patients between CT1 and CT2 the whole volume of all lesions remained unchanged. In $28.17 \%\left[40^{*}\right]$ it has increased and in 21.13\% it has decreased. Patients included in the study were treated with: Loop Diuretics, Aldosterone Antagonists, Thiazides, Thiazide-like Diuretics, ACE Inhibitors, ARBs, Beta-Blockers and Calcium Channel Blockers CT1 — computed tomography on admission; CT2 — computed tomography at discharge; NIHSS — National Institutes of Health Stroke Scale

Table II. Baseline characteristics of the study groups divided according to the assessment of the clinical status in National Institutes of Health Stroke Scale

\begin{tabular}{|l|c|c|c|}
\hline & NIHSS improvement $(\mathbf{n}=\mathbf{4 8 7})$ & NIHSS deterioration $(\mathbf{n}=\mathbf{2 2 5})$ & $\mathbf{P}$ \\
\hline Age (years) & $73.00[64.00-80.00]$ & $77.00[68.00-83.00]$ & $<0.001$ \\
\hline Sex (male) (\%) & 51.54 & $46-67$ & 0.23 \\
\hline NIHSS on admission & $5.00[3.00-9.00]$ & $5.00[2.00-23.00]$ & 0.72 \\
\hline NIHSS at discharge & $2.00[1.00-4.00]$ & $\begin{array}{c}3.00[2.00-8.00] \\
\mathrm{n}=138^{* *}\end{array}$ & $<0.001$ \\
\hline Rankin on admission & $4.00[3.00-4.00]$ & $\begin{array}{c}4.00[2.00-5.00] \\
3.00[2.00-4.00] \\
\mathrm{n}=138^{* *}\end{array}$ & $<0.56$ \\
\hline Rankin at discharge & $\begin{array}{c}2.00[1.00-3.00] \\
\mathrm{n}=485^{*}\end{array}$ & 6.22 & $<0.001$ \\
\hline Improvement in Rankin [\%] & $\begin{array}{c}76.18 \\
\mathrm{n}=486^{*}\end{array}$ & & 0.001 \\
\hline
\end{tabular}

${ }^{*}$ the data from the rest of patients were not achievable; ${ }^{*}$ in the rest of cases death was found

NIHSS - National Institutes of Health Stroke Scale

in RANKIN ( 1 1; $\mathrm{n}=385)$ and with deterioration or no change in RANKIN or patients who decreased $(\mathrm{R} 2 ; \mathrm{n}=327)$.

The study groups N1 and N2 had significantly different age, NIHSS score at discharge and Rankin score at discharge. The baseline characteristics of the study groups were presented in Table II. These study groups significantly differ in percentage of patients with stenosis of cervical arteries. There were also significant differences in the results of C-Reactive Protein (CRP [mg/l]; 4.75 [1.93-13.65] vs. 9.40 [2.08-41.72], $\mathrm{P}=0.001)$ and White Blood Cells (WBC $[103 / \mu \mathrm{L}] ; 8.58$ [7.15-10.40] and 9.02 [7.28-12.04], $\mathrm{P}=0.006$ ) between $\mathrm{N} 1$ and $\mathrm{N} 2$ respectively. The comparison of comorbidities between these groups was presented in Table III. The volume of stroke lesion in CT was significantly greater in N2. The results in CT were shown in Table IV.

The baseline characteristics of the study groups R1 and R2 were presented in Table V. There were significant differences in age, NIHSS score on admission and at discharge and Rankin score at discharge. The comparison in comorbidities between these groups was shown in the Table VI. These groups significantly differed in percentage of patients with stenosis of cervical arteries. There were significant differences in WBC (8.50 [6.99-10.39] vs. 9.00 [7.29-11.46], $\mathrm{p}=0.006)$ and CRP (4.20 [1.80-10.87] vs. 8.70 [2.09-37.70], $\mathrm{p}=0.000)$ between $\mathrm{R} 1$ and $\mathrm{R} 2$ respectively. The volume of stroke lesion in CT was significantly greater in R2 (Table VII). 
Table III. Comorbidities in the study groups divided according to the assessment of the clinical status in National Institutes of Health Stroke Scale

\begin{tabular}{|l|c|c|c|}
\hline Comorbidities & N1 $(\mathbf{n}=\mathbf{4 8 7})$ & N2 (n = 225) & P \\
\hline Ischemic stroke (\%) & 94.66 & 88.89 & 0.22 \\
\hline Carotid artery stenosis (\%) & 34.91 & 25.33 & 0.01 \\
\hline Thrombolysis (\%) & 10.72 & 8.44 & 0.63 \\
& $\mathrm{n}=485^{*}$ & 36.89 & 0.37 \\
\hline Myocardial infarction (\%) & 33.47 & 41.78 & 0.86 \\
\hline Diabetes type 2 (\%) & 40.95 & & 0.90 \\
\hline Obesity (\%) & $\mathrm{n}=486^{*}$ & 5.33 & 0.84 \\
\hline Smoking (\%) & 4.72 & 6.67 & \\
\hline
\end{tabular}

*the data from the rest of patients were not available

Table IV. The results in computed tomography in the study groups divided according to the assessment of the results in National Institutes of Health Stroke Scale

\begin{tabular}{|l|c|c|l|}
\hline & NIHSS improvement $(\mathbf{n}=487)$ & NIHSS deterioration $(\mathbf{n}=225)$ & P \\
\hline The sum of the volume of all lesions in CT1 $\left[\mathrm{cm}^{3}\right]$ & $\begin{array}{c}2.80[1.60-8.00] \\
\mathrm{n}=181^{*}\end{array}$ & $\begin{array}{c}6.00[2.65-19.85] \\
\mathrm{n}=88^{*}\end{array}$ & 0.001 \\
\hline The sum of the volume of all lesions in CT2 [cm $]$ & $\begin{array}{c}2.60[1.40-7.00] \\
\mathrm{n}=251^{*}\end{array}$ & $\begin{array}{c}6.24[2.08-26.88] \\
\mathrm{n}=103^{*}\end{array}$ & $<0.001$ \\
\hline $\begin{array}{l}\text { The difference of the volume of lesions between } \\
\text { CT1 and CT2 }\left[\mathrm{cm}^{3}\right]\end{array}$ & $\begin{array}{c}0.00[0.00-0.00] \\
\mathrm{n}=107^{*}\end{array}$ & $\begin{array}{c}0.00-4.50] \\
\mathrm{n}=35^{*}\end{array}$ & 0.03 \\
\hline The greatest lesion in CT 1 $\left[\mathrm{cm}^{3}\right]$ & $\begin{array}{c}2.70[1.60-7.00] \\
\mathrm{n}=181^{*}\end{array}$ & $\begin{array}{c}5.67[2.65-17.50] \\
\mathrm{n}=88^{*}\end{array}$ & 0.001 \\
\hline The greatest lesion in CT 2 $\left[\mathrm{cm}^{3}\right]$ & $\begin{array}{c}2.50[1.26-6.00] \\
\mathrm{n}=251^{*}\end{array}$ & $\begin{array}{c}6.00[2.08-23.68] \\
\mathrm{n}=103^{*}\end{array}$ & $<0.001$ \\
\hline
\end{tabular}

*the data from the rest of patients were not available

CT1 - computed tomography on admission; CT2 - computed tomography at discharge

Table V. Baseline characteristics of the study groups divided according to the results in Rankin scale

\begin{tabular}{|l|c|c|c|}
\hline & $\mathbf{R} 1 \mathbf{( n = 3 8 5 )}$ & $\mathbf{R 2}(\mathbf{n}=327)$ & $\mathbf{P}$ \\
\hline Age (years) & $73.00[64.00-80]$ & $77.00[68.00-83.00]$ & $<0.001$ \\
\hline Sex (male) (\%) & 52.99 & 46.48 & 0.084 \\
\hline NIHSS on admission & $5.00[3.00-8.00]$ & $6.00[3.00-13.00]$ & 0.02 \\
\hline NIHSS at discharge & $2.00[1.00-3.00]$ & $\begin{array}{c}4.00[2.00-8.00] \\
\mathrm{n}=240^{* *}\end{array}$ & $<0.001$ \\
\hline Improvement in NIHSS (\%) & 96.36 & 35.47 & $<0.001$ \\
\hline Rankin on admission & $4.00[3.00-4.00]$ & $4.00[3.00-5.00]$ & 0.83 \\
\hline Rankin at discharge & $\begin{array}{c}2.00[1.00-3.00] \\
\mathrm{n}=384^{*}\end{array}$ & $\begin{array}{c}3.00[2.00-5.00] \\
\mathrm{n}=239^{* *}\end{array}$ & $<0.001$ \\
\hline
\end{tabular}

*the data from the rest of patients were not achievable; **in the rest of cases death was found

R1 - patients with improvement in Rankin; R2 - patients with no change in Rankin, with deterioration and patients who was found death; NIHSS — National Institutes of Health Stroke Scale 
Table VI. Comorbidities in the study groups divided according to the assessment of the results in Rankin scale

\begin{tabular}{|l|c|c|c|}
\hline Comorbidities & $\mathbf{R 1}(\mathbf{n}=\mathbf{3 8 5})$ & $\mathbf{R 2}$ (n= 327) & P \\
\hline Ischemic stroke (\%) & 94.55 & 90.83 & 0.055 \\
\hline Carotid artery stenosis (\%) & 35.06 & 28.13 & 0.05 \\
\hline Thrombolysis (\%) & 11.49 & 8.26 & 0.15 \\
\hline Myocardial infarction (\%) & $\mathrm{n}=383^{*}$ & 35.47 & 0.63 \\
\hline Type 2 diabetes (\%) & 33.77 & 44.04 & 0.16 \\
& 38.80 & & 0.31 \\
\hline Obesity (\%) & $\mathrm{n}=384^{*}$ & 5.81 & 0.10 \\
\hline Smoking (\%) & 4.16 & 7.65 & \\
\hline
\end{tabular}

*the data from the rest of patients were not achievable

R1 — patients with improvement in Rankin; R2 - patients with no change in Rankin, with deterioration and patients who was found death

Table VII. The results in computed tomography in the study groups divided according to assessment of the results in Rankin scale

\begin{tabular}{|l|c|c|c|}
\hline & Rankin improved $(\mathbf{n}=385)$ & Rankin deteriorated $(\mathbf{n}=327)$ & $P$ \\
\hline The sum of the volume of all lesions in CT1 $\left[\mathrm{cm}^{3}\right]$ & $\begin{array}{c}2.75[1.60-6.60] \\
\mathrm{n}=134^{*}\end{array}$ & $\begin{array}{c}5.46[1.84-16.42] \\
\mathrm{n}=135^{*}\end{array}$ & $<0.01$ \\
\hline The sum of the volume of all lesions in CT2 $\left[\mathrm{cm}^{3}\right]$ & $\begin{array}{c}2.45[1.20-5.48] \\
\mathrm{n}=198^{*}\end{array}$ & $\begin{array}{c}6.04[2.00-26.12] \\
\mathrm{n}=156^{*}\end{array}$ & $<0.001$ \\
\hline $\begin{array}{l}\text { The difference of the volume of lesions between } \\
\text { CT1 and CT2 }\left[\mathrm{cm}^{3}\right]\end{array}$ & $\begin{array}{c}0.00-0.00] \\
\mathrm{n}=81^{*}\end{array}$ & $\begin{array}{c}0.00[0.00-2.40] \\
\mathrm{n}=61^{*}\end{array}$ & 0.09 \\
\hline The greatest lesion in CT 1 $\left[\mathrm{cm}^{3}\right]$ & $\begin{array}{c}2.75[1.60-6.00] \\
\mathrm{n}=134^{*}\end{array}$ & $\begin{array}{c}5.00[1.80-16.42] \\
\mathrm{n}=135^{*}\end{array}$ & 0.01 \\
\hline The greatest lesion in CT 2 $\left[\mathrm{cm}^{3}\right]$ & $\begin{array}{c}2.30[1.20-5.00] \\
\mathrm{n}=198^{*}\end{array}$ & $\begin{array}{c}6.00[2.00-24.28] \\
\mathrm{n}=156^{*}\end{array}$ & $<0.001$ \\
\hline
\end{tabular}

*the data from the rest of patients were not available

CT1 - computed tomography on admission; CT2 - computed tomography at discharge; R1 — patients with improvement in Rankin; R2 — patients with no change in Rankin, with deterioration and patients who decreased

The state and clinical course of the patients according to their age was analyzed. The NIHSS score on admission correlated with age $(\mathrm{R}=0.212, \mathrm{P}<0.05)$ (Figure 1$)$.

A significant correlation was observed between RANKIN on admission and age of participants $(\mathrm{R}=0.231, \mathrm{P}<0.05)$.

The results of laboratory tests of the whole group of patients with hypertension treated before stroke were evaluated. $51.97 \%$ of patients had CRP above the normal limit and $33.23 \%$ of patients had WBC above the normal range. The relation between the results in clinical scales and CT and values in laboratory tests was analyzed. A significant correlation between CRP and NIHSS on admission was observed $(\mathrm{R}=0.191, \mathrm{P}<0.05)$.

The sum of the volume of all lesions in CT2 was related to $C R P(R=0.17, P<0.05)$.

\section{Discussion}

The epidemiological records show that in 2005-2008 almost one-third of adults in the US suffered from hypertension, and less than a half of them had it sufficiently controlled. This may be associated with an increased mortality and complications rates including myocardial ischemia, strokes, heart failure or chronic kidney disease: all of which escalates public health system costs, up to $\$ 131$ billion annually [9].

The long period, prior to the hypertension complications development facilitates unfavourable structural and functional cerebral changes i.e.: vessels remodelling, blood-brain barrier integration, diffuse white matter damage, and also changes in the cerebral circulation, including vasodilatation, development of inflammation and oxidative stress or a dysfunction of the baroreceptor reflex [10]. Persistent elevated blood pressure has a considerable impact on the structure of brain arteries, triggering adaptive changes such as hypertrophy and remodeling [11]. Altogether, these mechanisms may contribute to the incident stroke.

Given the fact, that ischemic stroke affects also treated hypertensive patients (with more than 1 blood-lowering drug) [12], suggesting that effective treatment only reduces the risk. 


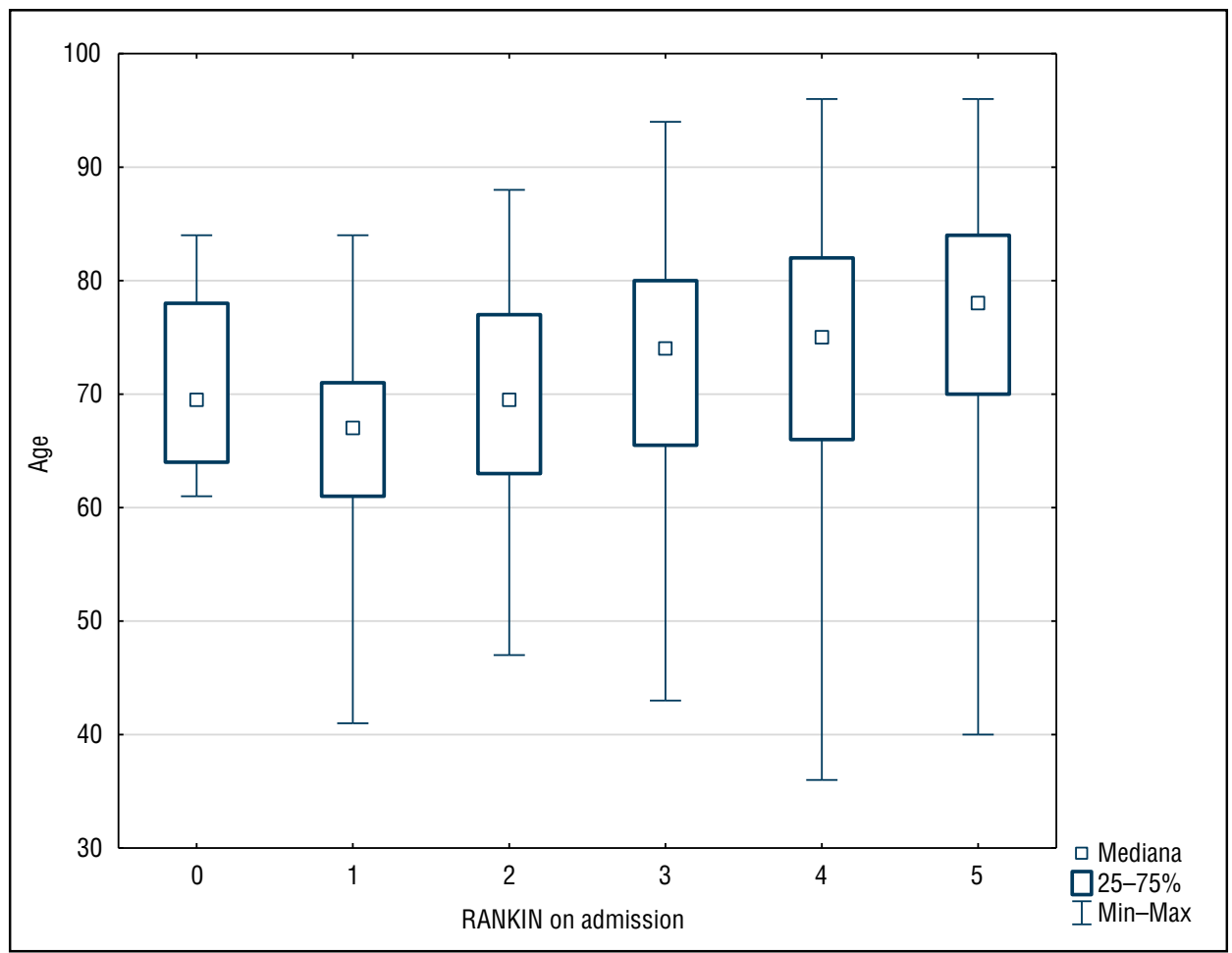

Figure 1. Presentation of the median and interquartile range for the age of patients

In our analysis, we found that women, experience stroke at the older age than men. The study of Holroyd-Leduc et al. conducted in a group of 44,832 patients with an acute stroke also indicated that men were younger than women [13]. This is in line with the results of other reports [14-16].

Interestingly, we have also found that the cardiovascular comorbidities incl. stenosis of the carotid arteries, myocardial infarction and $\mathrm{AF}$ are more common in women than in men. Niewada et al. findings indicating that in women AF more often coexists and the stroke is mainly caused by the embolic events (twice as often as in men) [15].

Part of these differences may be ascribed to sexual diversity and the influence of sex hormones may not be disregarded. The estradiol dilates vessels and increases the blood flow, while testosterone has the opposite effect, estrogens also have a positive influence on cerebrovascular reactivity and has anti-inflammatory properties [17]. Therefore, women after menopause, are actually deprived of this protective factor due to the lowering of the estrogens level.

Women with a stroke incident were more often admitted with a higher NIHSS score than men and at discharge in the Rankin assessment woman were worse than man. A study by Santalucia et al. conducted in 1272 stroke patients also showed, that the NIHSS result on admission was significantly worse in women, at discharge they were more often seriously neurologically impaired and the functional results in the mRS at discharge were also worse in comparison with man [16]. This is not completely understood, although one my hypothesize that older women are more often widows, socially isolated and lonely living and it's also suggested that women with an acute stroke more often than men show diffuse and non-specific symptoms, such as confusion, weakness, fatigue or consciousness changes. At admission women, more often present symptoms of aphasia, dysphagia and visual impairment [14-17].

The analyses indicate that both the NIHSS and Rankin results at admission are correlated with age. It is estimated that increase by, both in age and baseline NIHSS increase the chances for poor outcome in stroke survivors by 1.113 and 1.557 times, respectively [18].

Our study also has revealed that patients who showed improvement in NIHSS had significantly lower CRP levels, and WBC counts than patients who had no improvement in NIHSS upon discharge. The study of den Hertog et al. which evaluated the value of CRP in the very early stages of stroke - in the group of patients with $\geq 7 \mathrm{mg} / \mathrm{L}$ the NIHSS score upon admission was greater and they more often had AF which translated to cardioembolic strokes [19]. Similar results were observed by other groups [20]. 
VanGilder et al. demonstrated a positive correlation between an acute CRP increase with a long-term unfavourable outcome, assessed using NIHSS and $\mathrm{mRS}$ [21]. It is emphasized that an acute ischemic stroke may cause an increase in CRP levels depicting inflammatory response. This phenomenon, when present may be a poor predictor suggesting extensive tissue damage or co-existing infection additionally, it may correlate with the severity of stroke $[19,20]$. Similar results are also characteristic for the number of WBC, the level of which also increases in the course of acute stroke [19].

It is also important to emphasize that in a group of patients with no improvement or with deterioration in NIHSS and Rankin the volume of stroke lesion was greater than in patients with better results. The study of Yaghi et al. on 510 DWI positive patients revealed a graded relationship between the NIHSS result and median DWI lesion volume, what proves that people with minor stroke symptoms have relatively small brain infarcts documented in imaging studies [22]. It is worth to emphasize that despite no improvement in the size of stroke lesions during hospitalization the improvement in NIHSS scale was observed.

In our study, we also assessed the laboratory results of patients before the stroke incident, what indicated, that more than a half of them had elevated level of CRP, and almost $1 / 3$ of them - WBC above the normal range and there was a significant correlation between CRP and NIHSS on admission. The researchers indicate that the level of CRP taken within 12-24h of the onset of stroke is an independent predictor of unfavourable functional outcome of patients in the assessment after one year [21]. Researchers underline that CRP is both a risk and a prognostic factor for ischemic stroke and coronary events - mean CRP was significantly higher in stroke patients especially if stroke was caused by cardioembolism (3-fold increase in risk) and atherosclerosis of large arteries (2-fold increase in risk) [23]. It could be concluded that CRP may be a marker that could initiate basic preventive strategies in the future.

Lastly, it is worth mentioning that the level of CRP was significantly higher in the group of patients who did not improve the clinical condition, but our study also showed that their post-stroke changes in the brain were greater. Other researchers also indicate that the infarct volume is significantly positively correlated with serum CRP level [24]. We have noticed that inflammation was correlated with the magnitude of stroke lesion in CT at discharge, what may suggest that the severity of inflammation at admission indicates the number of cells that have already been damaged. Recent evidence suggests that blood biomarkers may be equally effective in predicting functional outcome as image biomarkers [21].

\section{Conclusions}

In conclusion we would like to underscore that hypertensive women experience first-ever stroke at older age as compared to men, however, the volume of brain ischemia at admission is greater in women than in men.

The clinical state of the patients assessed in NIHSS scale shows association with serum inflammatory markers which are coupled with.

The evident association between the volume of stroke lesion in CT and severity of inflammatory process.

Despite no changes in the volume of ischemic brain areas the improvement in NIHSS scale was observed. The easily available serum inflammatory marker seems to predict prognosis prior to brain CT-changes.

\section{Conflict of interest \\ There are no conflicts of interest.}

\section{References}

1. Sacco RL, Kasner SE, Broderick JP, et al. American Heart Association Stroke Council, Council on Cardiovascular Surgery and Anesthesia, Council on Cardiovascular Radiology and Intervention, Council on Cardiovascular and Stroke Nursing, Council on Epidemiology and Prevention, Council on Peripheral Vascular Disease, Council on Nutrition, Physical Activity and Metabolism. An updated definition of stroke for the 21 st century: a statement for healthcare professionals from the American Heart Association/American Stroke Association. Stroke. 2013; 44(7): 2064-2089, doi: 10.1161/STR.0b013e$318296 a e c a$, indexed in Pubmed: 23652265.

2. Sahathevan R, Brodtmann A, Donnan GA. Dementia, stroke, and vascular risk factors; a review. Int J Stroke. 2012; 7(1): 61-73, doi: 10.1111/j.1747-4949.2011.00731.x, indexed in Pubmed: 22188853.

3. Yang Q, Tong X, Schieb L, et al. Vital Signs: Recent Trends in Stroke Death Rates - United States, 2000-2015. MMWR Morb Mortal Wkly Rep. 2017; 66(35): 933-939, doi: 10.15585/mmwr. mm6635e1, indexed in Pubmed: 28880858.

4. Marshall IJ, Wang Y, McKevitt C, et al. Trends in risk factor prevalence and management before first stroke: data from the South London Stroke Register 1995-2011. Stroke. 2013; 44(7): 1809-1816, doi: 10.1161/STROKEAHA.111.000655, indexed in Pubmed: 23660847.

5. O'Collins VE, Donnan GA, Macleod MR, et al. Hypertension and experimental stroke therapies. J Cereb Blood Flow Metab. 2013; 33(8): 1141-1147, doi: $10.1038 / \mathrm{jcbfm} .2013 .88$, indexed in Pubmed: 23736641.

6. Ghandehari K. Challenging comparison of stroke scales. J Res Med Sci. 2013; 18(10): 906-910, indexed in Pubmed: 24497865.

7. Mancia G, Fagard R, Narkiewicz K, et al. Task Force Members. 2013 ESH/ESC Guidelines for the management of arterial hypertension: the Task Force for the management of arterial hypertension of the Eu- 
ropean Society of Hypertension (ESH) and of the European Society of Cardiology (ESC). J Hypertens. 2013;31(7): 1281-1357, doi: 10.1097/01. hjh.0000431740.32696.cc, indexed in Pubmed: 23817082.

8. Tykarski A, Narkiewicz K, Gaciong Z, et al. Guidelines for the Management of Hypertension. Arterial Hypertension. 2015; 19(2): 53-83, doi: 10.5603/ah.2015.0010.

9. Centers for Disease Control and Prevention (CDC). Vital signs: awareness and treatment of uncontrolled hypertension among adults-United States, 2003-2010. MMWR Morb Mortal Wkly Rep. 2012; 61: 703-709, indexed in Pubmed: 22951452.

10. Yu JG, Zhou RR, Cai GJ. From hypertension to stroke: mechanisms and potential prevention strategies. CNS Neurosci Ther. 2011; 17(5): 577-584, doi: 10.1111/j.1755-5949.2011.00264.x, indexed in Pubmed: 21951373.

11. Faraco G, Iadecola C. Hypertension: a harbinger of stroke and dementia. Hypertension. 2013; 62(5): 810-817, doi: 10.1161/HYPERTENSIONAHA.113.01063, indexed in Pubmed: 23980072.

12. Hippisley-Cox J, Coupland C, Brindle P. Derivation and validation of QStroke score for predicting risk of ischaemic stroke in primary care and comparison with other risk scores: a prospective open cohort study. BMJ. 2013; 346: f2573, indexed in Pubmed: 23641033.

13. Holroyd-Leduc JM, Kapral MK, Austin PC, et al. Sex differences and similarities in the management and outcome of stroke patients. Stroke. 2000; 31(8): 1833-1837, indexed in Pubmed: 10926943.

14. Jerath NU, Reddy C, Freeman WD, et al. Gender differences in presenting signs and symptoms of acute ischemic stroke: a population-based study. Gend Med. 2011; 8(5):312-319, doi: 10.1016/j. genm.2011.08.001, indexed in Pubmed: 21925968.

15. Niewada M, Kobayashi A, Sandercock PAG, et al. International Stroke Trial Collaborative Group. Influence of gender on baseline features and clinical outcomes among 17,370 patients with confirmed ischaemic stroke in the international stroke trial. Neuroepidemiology. 2005; 24(3): 123-128, doi: 10.1159/000082999, indexed in Pubmed: 15637449 .

16. Santalucia P, Pezzella FR, Sessa M, et al. Women Stroke Association (WSA). Sex differences in clinical presentation, severity and outcome of stroke: results from a hospital-based registry. Eur J Intern Med.
2013; 24(2): 167-171, doi: 10.1016/j.jim.2012.10.004, indexed in Pubmed: 23167980.

17. Reeves MJ, Bushnell CD, Howard G, et al. Sex differences in stroke: epidemiology, clinical presentation, medical care, and outcomes. Lancet Neurol. 2008; 7(10): 915-926, doi: 10.1016/S14744422(08)70193-5, indexed in Pubmed: 18722812.

18. Shrestha S, Poudel RS, Khatiwada D, et al. Stroke subtype, age, and baseline NIHSS score predict ischemic stroke outcomes at 3 months: a preliminary study from Central Nepal. J Multidiscip Healthc. 2015; 8: 443-448, doi: 10.2147/JMDH.S90554, indexed in Pubmed: 26491342.

19. den Hertog HM, van Rossum JA, van der Worp HB, et al. PAIS investigators. C-reactive protein in the very early phase of acute ischemic stroke: association with poor outcome and death. J Neurol. 2009; 256(12): 2003-2008, doi: 10.1007/s00415-009-5228-x, indexed in Pubmed: 19609738.

20. Christensen H, Boysen G. C-reactive protein and white blood cell count increases in the first 24 hours after acute stroke. Cerebrovasc Dis. 2004; 18(3): 214-219, doi: 10.1159/000079944, indexed in Pubmed: 15273437.

21. VanGilder RL, Davidov DM, Stinehart KR, et al. C-reactive protein and long-term ischemic stroke prognosis. J Clin Neurosci. 2014; 21(4): 547-553, doi: 10.1016/j.jocn.2013.06.015, indexed in Pubmed: 24211144.

22. Yaghi S, Herber C, Boehme AK, et al. The Association between Diffusion MRI-Defined Infarct Volume and NIHSS Score in Patients with Minor Acute Stroke. J Neuroimaging. 2017; 27(4): 388-391, doi: 10.1111 /jon.12423, indexed in Pubmed: 28066971.

23. Chaudhuri JR, Mridula KR, Umamahesh M, et al. High sensitivity C-reactive protein levels in Acute Ischemic Stroke and subtypes: A study from a tertiary care center. Iran J Neurol. 2013; 12(3): 92-97, indexed in Pubmed: 24250912.

24. Ormstad H, Aass HC, Lund-Sørensen N, et al. Serum levels of cytokines and C-reactive protein in acute ischemic stroke patients, and their relationship to stroke lateralization, type, and infarct volume. J Neurol. 2011; 258(4): 677-685, doi: 10.1007/s00415-011-60060, indexed in Pubmed: 21424610. 